\title{
Sex, Drugs, and a Few Other Things
}

\author{
Michael Ashby
}

Published online: 12 June 2017

(C) Journal of Bioethical Inquiry Pty Ltd. 2017

Keywords Bioethics · Reproductive technology - End of life $\cdot$ Dying $\cdot$ Drug dependence $\cdot$ Racial determinants of health $\cdot$ Medical migration

Bioethical content has a leaning towards the takings off and landings of life, alpha to omega, coming into the world and leaving it: the transitions. Transitions are often the most vulnerable times for journeys, as is the case in aviation, and bioethics is very much a giant mediation on our individual and collective vulnerabilities and a forum for exploration of difference and therefore also often, fear. Just as comedy deals with things we find hard to talk about, so "standup" bioethics seeks to shine a light into what is thought and done in the penumbra of life. A conference speaker once showed a cartoon of sperm and ovaries on a tombstone to make this point. In this issue we live up to that caricature. Politics also exists to deal with difference, and hence it is reasonable to ally bioethics with biopolitics, as our guest editor does in the title of this issue's symposium.

As our regular readers will know, a major feature of this journal is the regular publication of special symposia. We hope that these are useful "go-to" collections for teachers and students on specific topics. They afford our

\section{Ashby $(\bowtie)$}

Palliative Care Service, Royal Hobart Hospital, Tasmanian Health Service, and School of Medicine, Faculty of Health Sciences, University of Tasmania, 1st Floor, Peacock Building, Repatriation Centre, 90 Davey Street, Hobart, TAS 7000, Australia

e-mail: michael.ashby@ths.tas.gov.au authors and their audiences a chance to reflect deeply on themes of contemporary importance, that reflect some of the big ideas of our times and thereby, hopefully, act as a mirror to the "zeitgeist(s)" in which the world is immersed now and into the foreseeable future. In this issue, our Associate Editor Sylvia Camporesi (2017) introduces four papers from amongst our regular contributions which cohere around the various contentious aspects of reproduction (Browne 2017; Kendal 2017; Petropanagos 2017; Princewill et al. 2017). The title of her introduction talks of "presents" and "futures" with the intention of highlighting the plurality and tensions of this time of unprecedented technical possibilities in biomedicine, in fact in bio everything. Reproduction is self-evidently at the heart of human existence, and both modern and future possibilities bring happiness to some and anxiety to others, especially for monotheistic religions where the hand of god is not to be superseded by the hand of man - at least as a causal agent in the lifedefining natural world transitions. The joy of a child for the child-less, cures for dreadful or, at times, perhaps inconvenient, genetic or gender outcomes, the illusion of control, the fear of disturbing the natural order of things, all these perspectives are in tension at a personal, societal, and religious/ethical level.

Outside the symposium, and not too far distant in a technical sense from the controversies of reproductive technology, Lysaght et al. (2017) address the diversity of stem cell research frameworks and laws across different jurisdictions. These different regimes lead to the possibility for vulnerable people to attempt to go to places that have less regulation in order to access potential 
treatments that are not available in their home state. In some cases, these treatments, accessed by such "stem tourism" may be of poor efficacy and ethical regulation may be lacking. They argue for better international frameworks and understandings to prevent such potential exploitation, intended or not, whilst not losing the capacity for innovation and therapeutic progress.

However, the end of life is never far away. Frenette et al.'s paper (2017) from Quebec is reflective of a global concern to put in place policies and systems for limiting escalations of medical treatment for those who are approaching the end of their lives. As the frail aged population grows inexorably across the world, and chronic disease burden increases, encounters with health systems, set to a default of medical intervention for acute deterioration, are rising dramatically. This means that societies are spending large resources to purchase their dying citizens a medicalized death that distracts from appropriate care and necessary grief and adaptation. Setting appropriate goals of care, documenting them, and ensuring that they are adhered to, in acute hospitals and throughout the health system, is an ongoing task for policy and research to which these authors make a welcome practical contribution. Tedesco (2017) defends the Dutch, and most famously so-called Groningen, protocols for the end-of-life care of babies in neonatal intensive care with very poor prospects of life or quality of life. These have come in for harsh, and often uninformed, criticism by right to life activists across the world. These authors redress this balance, and by ethical argument, posit that any notoriety is ill founded. With the advances of modern neonatology, hard decisions will be needed more rather than less frequently as barriers of possibility are pushed. On a subject where end of life is also often the scenario in question, Courtwright et al. (2017) from Massachusetts General Hospital explore the role that clinical ethics committees and ethicists have (in the U.S. context) for "unrepresented" people who have no relative or substitute decision-maker. The ideal is of course to have a statutory guardianship structure that can step in and offer independent advocacy, but this may be time consuming and difficult. They caution against seeing the ethics committee as the default body to bear this responsibility alone. As social alienation, old age, and cognitive failure are on the rise everywhere, this problem will be common. Safe substitute decision-making systems need to be in place for the many people who either do not or cannot make these arrangements in advance. These need to be practical, rapidly deployable, safe, and transparent.

Matthews et al. (2017) address the complexities of substance abuse and its attendant social stigma. Everyday life is psychically tough everywhere, especially in the most prosperous countries of the world, where drug and alcohol issues are prominent causes of societal misery. The authors present an empirical account of the self-loathing and social construction of the drugdependent existence. Unfortunately, this lack of care for self and its causes in personal and social life probably also lie at the heart of the causes of addiction and dependence. Jacques Lacan (Phillips 2015) said that the Christian exhortation to love others as you love yourself expressed the problem of self-regard well, that the super ego often doesn't give the ego a chance before the internal beating up starts.

Anomaly (2017) examines the moral pitfalls of research into racial differences in health and disease. He examines the relationship between belief and action in the argument and the obvious danger of small racial genetic differences leading to stigmatization. It is important for knowledge about disease susceptibility and natural history in different racial groups to be recognized, especially for public health and preventative purposes. However, once again a paper shows the dangers of categorizing people and then treating them as the "other," leading to social exclusion, racism, and discriminations of all sorts. Such splitting and projection is an ever-present danger in the world, and bioethics clearly has a role in trying to understand, as these and many of our authors in this issue, and others, strive to do.

Wagner et al. (2017) discuss the dangers of increasing neuroimaging correlation with behaviour and social behaviours, including ethical reasoning. They speculate whether Kantian and utilitarian methods require different neural network activation, and that moral cognition tested by interpretations of electroencephalography (EEG) monitoring of brain activity is feasible and more practical than other modalities, but there are ethical pitfalls, particularly concerning privacy and use in the justice system. Such a reduction of complex human behaviour also needs to be seen as limited in the subjective realm at least, rather like dismantling a television monitor to explore the beauty of the picture. They conclude that future research needs to be multidisciplinary, and clear bioethical engagement in essential. 
In the Critical Commentary feature, Yuksekdag (2017) responds to a recent article by Mpofu, Gupta, and Hays (2016), concerning the ethics of medical practitioner migration, highlighting the needs of individual practitioners and their rights and freedoms. Together with our regular legal feature, Recent Developments (Furrow and Richards 2017) we hope this all gives you a good "read" on some important contemporary bioethical "enquiries."

\section{References}

Anomaly, J. 2017. Race research and the ethics of belief. Journal of Bioethical Inquiry 14(2). Doi: 10.1007 /s11673-017-9774-0.

Browne, K. 2017. How sex selection undermines reproductive autonomy. Journal of Bioethical Inquiry 14(2). Doi: 10.1007/s11673-017-9783-z.

Camporesi, S. 2017. Bioethics and biopolitics: Presents and futures of reproduction. Journal of Bioethical Inquiry 14(2). Doi: 10.1007/s11673-017-9787-8.

Courtwright, A.M., J. Abrams, and E. Robinson. 2017. The role of a hospital ethics consultation service in decision-making for unrepresented patients. Journal of Bioethical Inquiry 14(2). Doi: 10.1007/s11673-017-9773-1.

Frenette, M., J. Saint-Arnaud, and K. Serri. 2017. Levels of Intervention: How Are They Used in Quebec Hospitals? Journal of Bioethical Inquiry 14(2). Doi: 10.1007/s11673017-9778-9.

Furrow, B., and B. Richards. 2017. Regulating the new. Journal of Bioethical Inquiry 14(2). Doi: 10.1007/s11673-017-9785-x.
Kendal, E. 2017. The perfect womb: Promoting equality of (fetal) opportunity. Journal of Bioethical Inquiry 14(2). Doi: 10.1007/s11673-017-9775-z.

Lysaght, T., I.H. Kerridge, D. Sipp, G. Porter, and B.J. Capps. 2017. Ethical and regulatory challenges with autologous adult stem cells: A comparative review of international regulations. Journal of Bioethical Inquiry 14(2). Doi: 10.1007 /s11673-017-9776-y.

Matthews, S., R. Dwyer, and A. Snoek. 2017. Stigma and selfstigma in addiction. Journal of Bioethical Inquiry 14(2). Doi: 10.1007/s11673-017-9784-y.

Mpofu, C., T.S. Gupta, and R. Hays. 2016. The ethics of medical practitioner migration from low-resourced countries to the developed world: A call for action by health systems and individual doctors. Journal of Bioethical Inquiry 13(3): 395-406.

Petropanagos, A. 2017. Testicular tissue cryopreservation and ethical considerations: A scoping review. Journal of Bioethical Inquiry 14(2). Doi: 10.1007/s11673-017-9781-1.

Phillips, A. 2015. Against self-criticism. London Review of Books 37(5): 13-16.

Princewill, C.W., A.S. Jegede, T. Wangmo, A. Riecher-Rössler, and B.S. Elger. 2017. Autonomy and reproductive rights of married Ikwerre women in Rivers State, Nigeria. Journal of Bioethical Inquiry 14(2). Doi: 10.1007/s11673-017-9779-8.

Tedesco, M. 2017. Dutch protocols for deliberately ending the life of newborns: A defence. Journal of Bioethical Inquiry 14(2). Doi: 10.1007/s11673-017-9772-2.

Wagner, N-F., P. Chaves, and A. Wolff. 2017. Discovering the neural nature of moral cognition? Empirical, theoretical, and practical challenges in bioethical research with electroencephalography (EEG). Journal of Bioethical Inquiry 14(2). Doi: 10.1007/s11673-017-9780-2.

Yuksekdag, Y. 2017. Against cursory treatments in ethics of medical migration from underserved countries. Journal of Bioethical Inquiry 14(2). Doi: 10.1007/s11673-017-9782-0. 